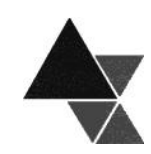

\title{
Pescado: importância nutricional e consumo no Brasil
}

\author{
Alan Giovanini de Oliveira Sartori ${ }^{1}$, Rodrigo Dantas Amancio ${ }^{2}$
}

O pescado é um alimento que se destaca nutricionalmente quanto à quantidade e qualidade das suas proteínas, à presença de vitaminas e minerais e, principalmente, por ser fonte de ácidos graxos essenciais ômega-3 eicosapentaenoico (EPA) e docosaexaenoico (DHA). O consumo desses lipídios é associado à redução do risco de doenças cardiovasculares e a funções importantes nas fases iniciais do desenvolvimento humano. No Brasil, os autores têm concentrado suas análises sobre consumo de pescado com base em dados obtidos em localidades da região Norte, que apresenta elevada disponibilidade do alimento em relação às demais regiões brasileiras. $\mathrm{O}$ objetivo do presente artigo foi analisar a importância nutricional do pescado e o consumo no Brasil, discriminando-o de acordo com as regiões geográficas. Foi possível inferir que: a ingestão regular de pescado traz benefícios à saúde humana e que o risco de contaminação por elemento químico é considerado baixo; o consumo é reduzido, com exceção das regiões Norte e Nordeste, e não houve ampliação no período de 1970 a 2009; há distinção entre as quantidades ingeridas (per capita) e a diversidade de espécies preferidas, de acordo com as regiões.

Palavras-chave: pescado, nutrição, consumo, disponibilidade, hábitos alimentares.

\section{Fish: nutritional relevance and consumption in Brazil}

Fish is a food that nutritionally outstands for its proteins, micronutrients and, mainly, because it is a source of omega-3 fatty acids eicosapentaenoic (EPA) and docosahexaenoic (DHA). The consumption of these fatty acids is associated with lower risks of cardiovascular diseases and with important functions during the first human development phases. In Brazil, authors have focused their analysis about fish consumption on data collected in communities from North region that shows high levels of availability, compared to the other geographic Brazilian regions. The aim of this article was to analyze the nutritional relevance of fish ingestion in humans and the consumption in Brazil and in its geographic regions. It was possible to infer that: regular ingestion of fish meat is related to benefits on human health and that risks associated with chemical elements are low; the consumption is reduced, except in the North and Northeast regions, and it was not amplified in the period from 1970 until 2009; there are differences among the quantity ingested (per capita) and the variety of fish species available for individuals from the five Brazilian geographic regions.

Key-words: fish, nutrition, consumption, availability, food habits.

\footnotetext{
${ }^{1}$ Mestrando do Programa de Pós-graduação em Ciência e Tecnologia de Alimentos, Departamento de Agroindústria, Alimentos e Nutrição - Escola Superior de Agricultura Luiz de Queiroz (ESALQ), Universidade de São Paulo (USP), Piracicaba, SP. Bolsista Coordenação de Aperfeiçoamento de Pessoal de Nível Superior (CAPES). Correspondência: Travessa Dona Eugênia, 135, apto 44, São Dimas, CEP: 13.416-218. E-mail: alangosartori@gmail.com. Telefone: (11) $98432-4421$.

${ }^{2}$ Rodrigo Dantas Amancio. Mestre em Ciências. Área de concentração: Ciência e Tecnologia de Alimentos. Departamento de Agroindústria, Alimentos e Nutrição, ESALQ (USP).
} 


\section{INTRODUÇÃO}

Os peixes e os produtos obtidos por meio da atividade da pesca destacam-se nutricionalmente de outros alimentos de origem animal. Eles contêm, comparativamente, grandes quantidades de vitaminas lipossolúveis A e $\mathrm{D}$, minerais cálcio, fósforo, ferro, cobre, selênio e, no caso dos peixes de água salgada, iodo. A composição lipídica dos peixes contrasta com a de mamíferos por conter elevada proporção de ácidos graxos poli-insaturados de cadeia longa com cinco ou seis duplas ligações (mais de $40 \%$ ), o que impacta tanto na saúde (atividade benéfica antitrombótica), quanto na tecnologia aplicada durante o processamento destes alimentos (rápida deterioração e rancificação). As proteínas contêm todos os aminoácidos essenciais para o ser humano e, assim como as proteínas do leite, do ovo e de carnes de mamíferos, têm elevado valor biológico. Adicionalmente, são excelentes fontes de aminoácidos lisina, metionina e cisteína, encontrados em baixa quantidade em dietas a base de grãos de cereais ${ }^{[1]}$.

O valor nutricional do pescado e a divulgação de estudos que o associam com melhorias para a saúde têm causado, nos últimos anos, um aumento de interesse por esse alimento [2]. Dentre os possíveis benefícios da ingestão de uma ou duas porções de peixe por semana, que contêm cerca de $2 \mathrm{~g}$ de ácidos graxos poli-insaturados ômega-3, estão a redução do risco de Acidente Vascular Cerebral (AVC), de depressão, do Mal de Alzheimer e de morte por doença cardíaca [3]. A Food and Agriculture Organization (FAO) [4] preconiza a ingestão de pescado duas ou mais vezes por semana.

O consumo de pescado pode ser influenciado por diversos fatores, dos quais se destacam os socioeconômicos, os padrões de consumo alimentar, características pessoais, estado de saúde e dimensões atitudinais [5]. Registra-se que o consumo mundial de pescado aumentou de $10 \mathrm{~kg} /$ per capita/ano (em 1965) para $17 \mathrm{~kg} /$ per capita/ano (em 2007) [4].

Para vias de definição, o termo pescado abrange, segundo o Regulamento de Inspeção Industrial e Sanitária dos Produtos de Origem Animal (RIISPOA), por meio do Decreto no 30.691, de 1952: peixes, crustáceos, moluscos, anfibios e quelônios, habitantes dos meios aquáticos, de água doce ou salgada, desde que destinados à alimentação humana [${ }^{[0]}$.
No Brasil, os trabalhos científicos enfatizam dados obtidos para a região Norte, que apresenta consumo reconhecidamente superior em relação às demais regiões.

Com base nessas considerações, o presente artigo tem o objetivo de, por meio de revisão de literatura e de dados disponíveis, analisar a importância do pescado na nutrição humana e o consumo pela população brasileira, discriminando-o de acordo com as regiões geográficas, assim como a evolução entre os anos de 1970 e 2009.

\section{COMPOSIÇÃO E ASPECTOS NUTRICIONAIS}

Segundo Stansby [7], a carne de peixe pode ser incluída na dieta por ser: 1) um alimento com baixo teor de gordura (incluindo o colesterol) e alto teor protéico; 2) fonte de componentes nutricionais, como as vitaminas e minerais, e de ácidos graxos poliinsaturados.

Bang \& Dyerberg ${ }^{[8]}$ e Bang et al. ${ }^{[9]}$ publicaram na década de 1970 estudos sobre populações de esquimós que apresentavam baixa incidência de doenças cardiovasculares e de câncer, apesar da dieta rica em gorduras. Posteriormente, outros estudos epidemiológicos confirmaram os efeitos benéficos da carne de peixe e mostraram que outras populações que consumiam maior quantidade de peixe, além dos esquimós, apresentavam menor incidência de doenças cardiovasculares do que populações com ingestão menor desse alimento [10].

Os peixes são compostos basicamente por água, lipídios e proteínas, cujas quantidades variam entre as espécies. A fração lipídica é a que mais oscila, também ao longo do ciclo de vida em uma mesma espécie, chegando aos valores mínimos durante o período de ovulação. A fração de carboidratos no músculo dos peixes é baixa, geralmente menor que 0,5\%, e é típica nos músculos estriados, aonde ocorre como glicogênio e como um dos constituintes dos nucleotídeos. No final do ciclo de vida esta fração torna-se fonte de ribose livre, após autólise post mortem [1].

O pescado é uma fonte protéica importante, tanto quantitativa, quanto qualitativamente. Considerando uma variação entre as espécies, o teor sobre a composição total é alto - entre $15 \%$ e $25 \%$. 
Qualitativamente, apresenta todos os aminoácidos essenciais, com elevado teor em lisina, aminoácido starter do processo digestivo. A digestibilidade é alta, acima de $95 \%$, conforme a espécie, e maior do que das carnes em geral e do leite. $\mathrm{O}$ valor biológico, determinado pela alta absorção dos aminoácidos essenciais, é próximo de 100. Em decorrência do processamento, como é o caso do congelamento, a qualidade protéica do pescado é mantida, no entanto um descongelamento errôneo pode levar à extração de parte das proteínas. No enlatamento por meio do processo de Alta Temperatura Curto Tempo (HTST High Temperature Short Time) também não ocorrem perdas protéicas ${ }^{[1]}$.

O pescado é, em geral, uma boa fonte de vitaminas do complexo $\mathrm{B}$, cujo conteúdo é comparável ao encontrado em carnes de mamíferos, e também de vitaminas $\mathrm{A}$ e $\mathrm{D}$, no caso de peixes, como a sardinha, salmão e cavala, considerados mais gordurosos. No entanto, alguns peixes de água doce, como as carpas, possuem baixa concentração de tiamina (vitamina $B_{1}$ ). Quanto aos minerais, a carne de pescado é fonte conhecida principalmente de cálcio e de fósforo, mas também de ferro, cobre e selênio, além de iodo, para os peixes de água salgada. É notável, nesse alimento, o relativo baixo teor de sódio, que o torna opção viável em dietas restritivas para este mineral. Em peixes cultivados na aquicultura, os conteúdos de vitaminas e minerais correspondem, em termos gerais, aos teores destes elementos na alimentação que eles recebem, e é recomendada a adição de vitamina $\mathrm{E}$, que tem função antioxidante e contribui com a estabilidade dos ácidos graxos poli-insaturados ômega-3 [12].

Os ácidos graxos ômega-3 não são sintetizados pelo organismo humano e devem ser obtidos por meio da dieta. Eles integram a composição das membranas celulares e afetam a função dos receptores celulares nessas membranas, além de indicar o ponto inicial para a produção de hormônios que regulam a coagulação sanguínea e a contração e relaxamento das paredes arteriais. Eles também se ligam em receptores celulares que regulam funções genéticas. Os três ácidos graxos ômega-3 mais importantes para a dieta humana são: o eicosapentaenoico (EPA) e docosaexaenoico (DHA), provenientes principalmente de peixes marinhos e, ainda, o alfa-linolênico (ALA), o mais comum ácido graxo ômega-3 encontrado nas dietas ocidentais, oriundo de óleos vegetais e de nozes, semente e óleo de linhaça, vegetais folhosos e na gordura de animais, especialmente aqueles alimentados com grama. A conversão de ALA em EPA e DHA é limitada [3].

Os peixes de água doce, quando comparados com aqueles de água salgada, têm como principal característica os elevados níveis de ácidos graxos poliinsaturados C-16 e C-18 e baixos níveis de C-20 e C-22 (entre eles, o EPA e o DHA) [13,14]. Pesquisas, porém, têm indicado que peixes de água doce contêm relativamente elevados níveis de ácidos graxos eicosapentaenoicos e docosaexaenoicos [15,16]. A Tabela 1 mostra as quantidades de ácidos graxos ômega-3 EPA e DHA presentes em alguns dos peixes mais consumidos no país entre 2008 e 2009. A European Food Safety Authority (EFSA) [17] propõe um valor de referência diário per capita para consumo de ácidos graxos ômega-3 de cadeia longa EPA e DHA de 0,25 g para populações saudáveis.

Até a década de 1970 poucos pesquisadores analisaram os efeitos dos ácidos graxos ômega-3 na saúde humana. Em 1978 e 1979, Dyerberg et al. [20] e Dyerberg \& Bang [21], respectivamente, divulgaram o papel do ácido graxo eicosapentaenoico (EPA) na prevenção de ataques cardíacos, devido à ação antitrombótica e aumento no tempo de coagulação e seus efeitos na diminuição da concentração do colesterol sérico ${ }^{[10]}$.

As evidências mais fortes de um efeito benéfico dos ácidos graxos ômega-3 estão relacionadas com doenças cardíacas [3]. Kris-Etherton et al. [22] reuniram estudos epidemiológicos e testes clínicos e concluíram que a suplementação de EPA+DHA entre 0,5 e $1,8 \mathrm{~g}$ por dia (tanto como gordura de peixe, quanto na forma de suplemento alimentar) reduziu significativamente o risco de morte por essas doenças. Segundo os referidos autores, os testes clínicos demonstraram a relação entre ácidos graxos ômega-3 e a redução de eventos cardíacos, AVC e infarto do miocárdio não fatais e o retardo no progresso da aterosclerose em pacientes cardíacos. Leaf [23] reuniu trabalhos científicos que mostraram que o consumo frequente de peixe aparentemente reduz o número de mortes causadas por doenças cardiovasculares, como as arritmias. Segundo o autor, ácidos graxos ômega-3 também contribuem para a diminuição da pressão sanguínea e do ritmo cardíaco (melhora da circulação sanguínea) e, em maior dosagem, atuam na diminuição do teor de triglicerídeos e podem interromper inflamações, que desempenham importante função no desenvolvimento de aterosclerose. 
Tabela 1. Quantidade de ácidos graxos saturados, insaturados, EPA e DHA* de algumas das espécies mais consumidas no Brasil entre 2008 e 2009

\begin{tabular}{l|c|c|c|c|c|c}
\hline \multicolumn{1}{c|}{ Pescado } & Fonte & $\begin{array}{c}\text { Ácidos } \\
\text { graxos } \\
\text { saturados }\end{array}$ & $\begin{array}{c}\text { Ácidos } \\
\text { graxos } \\
\text { monoinsaturados }\end{array}$ & $\begin{array}{c}\text { Ácidos graxos } \\
\text { poli- } \\
\text { insaturados }\end{array}$ & EPA & DHA \\
\hline Pescada fresca & Água salgada & 0,8 & 2,4 & 0,9 & 0,18 & 0,43 \\
Camarão fresco & Água salgada & 0,1 & 0,1 & 0,2 & 0,08 & - \\
Corvina fresca & Água salgada & 0,7 & 0,5 & 0,1 & 0,03 & 0,04 \\
Sardinha em conserva & Água salgada & 4,1 & 5,5 & 11,9 & 0,44 & 0,46 \\
Sardinha fresca & Água salgada & 1,7 & 0,5 & 0,2 & 0,03 & 0,06 \\
Bacalhau fresco & Água salgada & 0,6 & 0,3 & 0,2 & 0,02 & 0,06 \\
Tucunaré fresco & Água doce & 0,6 & 0,4 & 0,4 & - & 0,12 \\
Merluza fresca ou congelada & Água salgada & 0,9 & 0,5 & 0,4 & 0,03 & 0,11 \\
\hline
\end{tabular}

* quantidade (em gramas) em 100 gramas de alimentos.

Fonte: Elaboração dos autores, com base nos dados disponibilizados pelo IBGE [18] e da Tabela Brasileira de Composição de Alimentos (TACO) [19].

Parte dos ácidos graxos ingeridos pelo ser humano integram os fosfolipídios das membranas celulares. Fosfolipídios contendo ácidos graxos poliinsaturados são mais susceptíveis à peroxidação lipídica (processo biológico que gera radicais livres, como o peróxido de hidrogênio) do que os que são constituídos por ácidos graxos com ausência ou menor número de saturações [24]. Entretanto, estudo recente [25], concluiu que a quantidade de enzimas glutationa peroxidase dependente de selênio GPx1 e GPx4 presentes na carne de peixes marinhos pode estar correlacionada com o conteúdo de ácidos graxos poli-insaturados nesse alimento. Essas enzimas têm função protetora que inibe o início da oxidação lipídica (GPx1) e repara os fosfolipídios oxidados (GPx4).

O suprimento de ácidos graxos ômega-3 nas dietas das culturas ocidentais, no entanto, vem diminuindo com a modernização da agricultura e da aquicultura. A relação entre ácidos graxos poliinsaturados ômega-3 e ômega-6 tem caído ao longo da evolução humana, de estimados 1:1 para 1:10 até 1:25, com base em várias estimativas [10].

O consumo de pescado, particularmente de peixes gordurosos, uma ou duas vezes por semana é recomendado, por serem ricos em EPA e DHA. Essa recomendação é especialmente importante para gestantes e para mulheres que planejam engravidar.
Do terceiro trimestre até o segundo ano de vida, uma criança necessita de um suprimento constante de DHA para a formação do cérebro e de outras partes do sistema nervoso. Nos Estados Unidos da América, muitas mulheres justificam a não ingestão de pescado devido à preocupação com a contaminação por mercúrio e por outros produtos, mas as evidências sobre os danos causados pelo baixo consumo de ácidos graxos ômega-3 são mais consistentes [26]. O consumo de pescado está associado à contaminação de mercúrio em seres humanos [27]. No Brasil, Kitahara et al. ${ }^{[28]}$ analisaram a quantidade de mercúrio presente em amostras $(n=$ 147) de 11 espécies de peixe de água doce capturadas nos Estados de São Paulo, Santa Catarina e Amazonas. Os autores não observaram níveis de mercúrio acima do permitido pela legislação brasileira (entre 0,5 e $1 \mathrm{mg} / \mathrm{kg}$ ) em nenhuma amostra. O mesmo resultado foi obtido por Morgano et al. [29], que avaliaram os níveis do elemento químico em peças de peixe de água doce $(n$ = 293) provenientes de pesqueiros e pisciculturas de 39 regiões do Estado de São Paulo. Morgano et al. [30], por meio de amostra $(n=257)$ de 39 espécies de peixes de água salgada, coletadas em oito pontos da cadeia produtiva de pescado da região da Baixada Santista (barco, entreposto, indústria, mercado municipal, mercado atacadista, peixaria, feira livre e 
supermercado), não obtiveram em 99,2\% das amostras quantidade de mercúrio que indicasse contaminação.

\section{DISPONIBILIDADE E CONSUMO NO BRASIL}

O IBGE, por meio da Pesquisa de Orçamentos Familiares (POF) 2008/2009, levantou dados sobre a aquisição domiciliar monetária e não monetária per capita média de alimentos no Brasil. Foram realizadas entrevistas em uma amostra representativa dos domicílios $(n=55.970)$ das grandes regiões (Norte, Nordeste, Sul, Sudeste e Centro-Oeste), considerando a situação domiciliar (urbano e rural), ao longo dos quatro trimestres de um ano. Os dados foram obtidos por meio do preenchimento de um questionário com informações de alimentos adquiridos por sete dias consecutivos. De acordo com a pesquisa, a aquisição domiciliar per capita média de pescado no Brasil foi estimada em $4 \mathrm{~kg}$ por ano, sendo que no meio urbano, esse valor atingiu 3,3 $\mathrm{kg}$ e no meio rural, $7,6 \mathrm{~kg}$. Considerando a origem das espécies, cada brasileiro adquiriu $1,57 \mathrm{~kg}$ de pescado de água doce e 1,91 $\mathrm{kg}$ de pescado de água salgada [18].

A mesma pesquisa (POF 2008/2009) publicou um módulo inédito de consumo alimentar pessoal, que foi realizado com uma subamostra representativa $(n=$ 34.003) de indivíduos com 10 anos de idade ou mais. O uso de um questionário, aonde foi feito o registro progressivo do consumo efetivo de alimentos e de bebidas ao longo de 24 horas, foi o instrumento metodológico adotado para a obtenção de dados de consumo pessoal. $\mathrm{O}$ valor atingido para a ingestão de pescado foi de $10 \mathrm{~kg}$ per capita por ano, sendo que $10,1 \%$ foram consumidos fora do domicílio [31]. A quantidade publicada no módulo de consumo pessoal da POF 2008-2009 aproxima-se da quantidade de pescado disponível per capita/ano no país, que é um dado estimado pela Faostat [32], base de dados da FAO: $8,3 \mathrm{~kg}$, em 2009. Para obter este valor, o órgão das Nações Unidas considerou o volume de produção e estoques agropecuários. A Faostat é abastecida, pelos países, por meio do registro de dados gerados e encaminhados pelos governos ou entidades não governamentais.

Outra fonte de dados que integra a presente análise é o Boletim Estatístico da Pesca e Aquicultura -
Brasil 2010, divulgado pelo Ministério da Pesca e Aquicultura (MPA) e organizado por meio do Sistema Nacional de Pesca e Aquicultura (SINPESQ), em parceria com a Secretaria Especial de Aquicultura e Pesca (SEAP/PR), Instituto Brasileiro de Geografia e Estatística (IBGE), Ministério do Meio Ambiente, Instituto Brasileiro do Meio Ambiente e dos Recursos Naturais Renováveis (IBAMA) e Instituto Chico Mendes de Conservação da Biodiversidade (ICMBio). Neste documento constam dados estimados e informações sobre a produção de pescado, assim como das importações e exportações no país. O consumo per capita "aparente" foi obtido a partir do total produzido somado ao total importado e subtraído o total exportado. Segundo este documento, considerando-se o ano de 2009, o consumo "aparente" (sem considerar as perdas) no Brasil foi de $9 \mathrm{~kg} /$ per capita/ano [33].

Apesar das variações entre os dados de abrangência nacional, obtidos por meio de diferentes métodos, o consumo de pescado no Brasil está aquém do recomendado (pelo menos $12 \mathrm{~kg}$ per capita por ano) pela Organização Mundial da Saúde (OMS) [34,35]. Possíveis motivos para isso são os preços elevados e a baixa qualidade, resultante de problemas de manipulação na comercialização in natura, conservação e armazenamento ${ }^{[36]}$.

Sonoda [37], por meio de dados integrantes da POF 2002/2003, analisou a aquisição de pescado, de acordo com os diferentes estratos de renda. $\mathrm{O}$ autor observou que esta se encontrava concentrada em domicílios com os menores rendimentos das regiões Norte e Nordeste e em domicílios que integravam os estratos intermediários de renda nas demais regiões.

Segundo dados de aquisição domiciliar do IBGE, por meio da POF 2008-2009 [18], as espécies de peixes mais adquiridas foram pescada, camarão, tambaqui, sardinha em conserva, curimatã, corvina, filés de pescado de espécies não identificadas congelados, sardinha fresca, jaraqui e tainha. Com exceção da sardinha em conserva e dos filés de pescado de espécies não identificadas congelados, as demais foram adquiridas frescas.

A evolução da quantidade de pescado disponível mundialmente e no Brasil per capita/ano é apresentada na Figura. Para esta análise, foi utilizada a base de dados Faostat [32], da FAO. O período compreendido foi 1970-2009. 
Figura. Quantidade* de pescado disponível mundialmente e no Brasil per capita por ano, entre 1970 e 2009

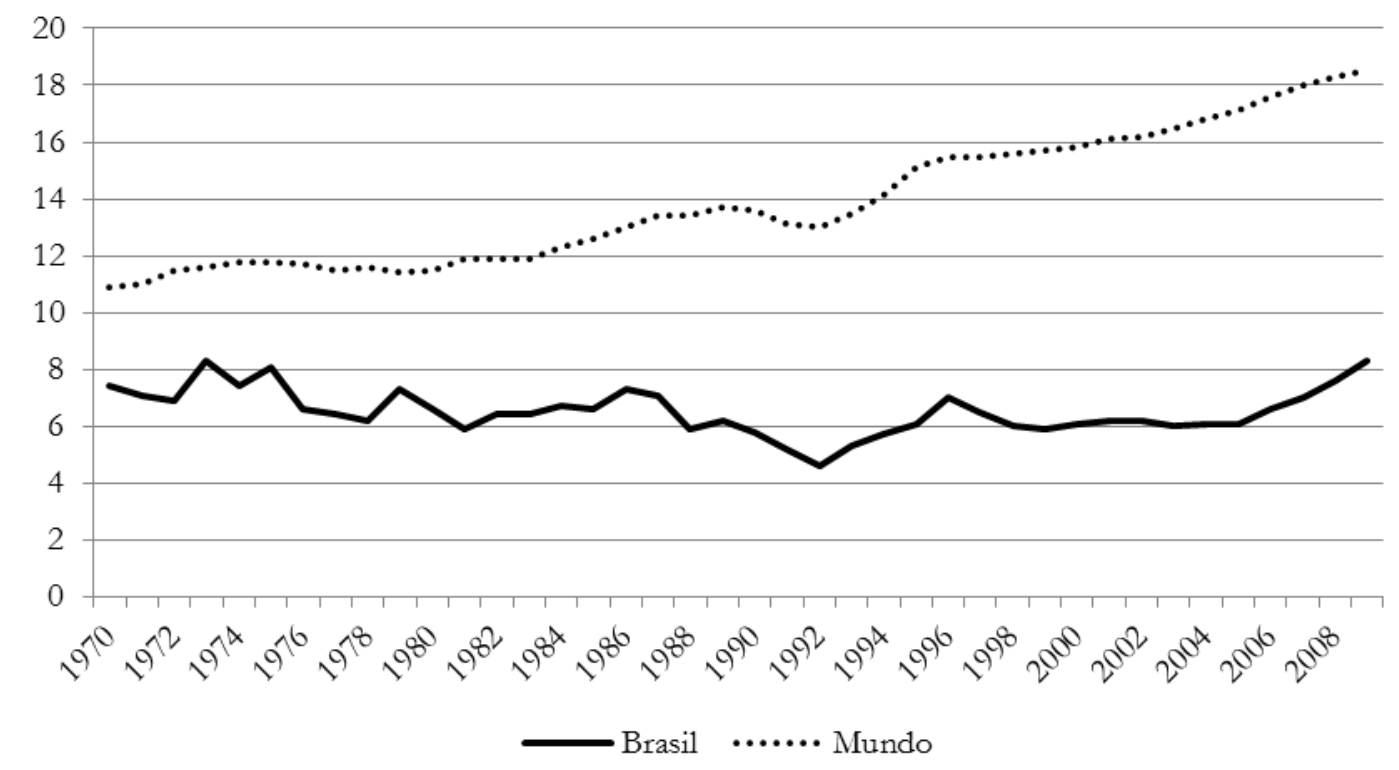

* Quantidade em quilograma.

Fonte: Faostat [32].

Nota-se que o crescimento mundial da disponibilidade do alimento, no período considerado, foi sistemática. No Brasil, houve oscilações e tendência de queda entre os anos 1970 e 1992. A partir do ano seguinte, 1993, houve tendência de ampliação na disponibilidade per capita/ano do alimento. Levy-Costa et al. ${ }^{[38]}$ avaliaram a evolução da participação relativa de alimentos no total de quilocalorias/per capita/dia, determinado por meio da aquisição alimentar domiciliar, nas áreas metropolitanas brasileiras e no município de Goiânia no período 1974-2003. As fontes de dados foram inquéritos nacionais de orçamento familiar. Os seguintes valores foram encontrados para carnes de peixes: $0,8 \%$ de $1.700 \mathrm{kcal}$ em $1974-1975,0,6 \%$ de $1.895 \mathrm{kcal} \mathrm{em} 1987-1988,0,5 \%$ de $1.695 \mathrm{kcal} \mathrm{em}$ 1995-1996, e 0,5\% de $1.502 \mathrm{kcal}$ em 2002-2003. Comparativamente, a participação de carne bovina era 4,4\% em 1974-1975 e 5,4\% em 2002/2003. Com base nos resultados, os autores inferiram que a participação relativa de carnes de peixe na dieta caiu $50 \%$ no período considerado.

Em 2007, com o objetivo de incentivar hábitos alimentares saudáveis, ampliar a disponibilidade de pescado e favorecer a atividade de criadores de pescado de pequeno porte, o Fundo Nacional de Desenvolvimento da Educação (FNDE), órgão que coordena o Programa Nacional de Alimentação Escolar, e a SEAP/PR estabeleceram uma parceria técnico-científica para a inclusão do pescado na alimentação oferecida a alunos de escolas públicas e filantrópicas. Inquérito realizado pelo MPA em 2012, porém, mostrou que apenas 26,9\% dos 5.565 municípios brasileiros oferecem pescado em seu cardápio ao menos uma vez por semana [39]. O consumo do alimento por crianças e adolescentes em idade de frequentar a escola também é classificado como baixo.

Danelon ${ }^{[40]}$ teve como objetivo identificar a análise do consumo alimentar de crianças e adolescentes e o acesso destes aos serviços de alimentação existentes nas unidades de ensino do município de Campinas. Foram aplicados o método recordatório de 24 horas e questionários específicos em uma amostra de alunos $(n=324)$ com idade entre seis e 14 anos. A autora identificou uma adesão ao PNAE de $75,3 \%$ e destes, $51 \%$ com frequência entre quatro e cinco vezes por semana. A participação no valor energético total da dieta para pescado entre os escolares foi baixa $(0,3 \%)$, apesar da elevada participação de produtos de origem animal.

Caroba ${ }^{[41]}$ analisou, por meio da aplicação de questionário e do método recordatório de 24 horas, as 
preferências alimentares de uma amostra de escolares adolescentes $(n=578)$ matriculados em escolas públicas do município de Piracicaba. Para o grupo de alimentos denominado "Peixe", o resultado foi uma baixa frequência de citação de consumo habitual (24,3\% dos entrevistados).

\section{DIFERENÇAS ENTRE A DISPONIBILIDADE E CONSUMO, DE ACORDO COM AS REGIÕES GEOGRÁFICAS}

A aquisição domiciliar e o consumo pessoal de pescado no Brasil, de acordo com os dados da POF 2008/2009, têm perfis diferenciados, quantitativa e qualitativamente, de acordo com as grandes regiões geográficas: Norte, Nordeste, Sul, Sudeste e CentroOeste. A Tabela 2 mostra dados da quantidade consumida por ano.

Nota-se que há um contraste na quantidade consumida entre a região Norte, com $38,1 \mathrm{~kg} /$ per capita/ano, e as regiões Sudeste, Sul e Centro-Oeste, com 5,5 kg, 3,1 kg e 3,4 kg, respectivamente. O consumo no Nordeste é comparativamente alto em relação aos valores médios (nacional). Segundo Sonoda [37, no período 2002-2003, 60\% dos moradores que adquiriram pescado encontravam-se nas regiões Norte e Nordeste, cuja população representava $35,7 \%$ da população do país.

O elevado consumo nas regiões Norte e
Nordeste é influenciado pela produção comparativamente elevada nessas regiões. Sendo alimentos altamente perecíveis, são necessários cuidados especiais (da captura até o consumo humano) para evitar a deterioração dos pescados ao longo da cadeia produtiva. Nas áreas próximas da produção, o pescado pode ser consumido num espaço curto de tempo, apresentando melhor qualidade (sensorial, microbiológica e nutricional) e menores preços. $\mathrm{O}$ transporte para outros consumidores distantes do local de produção e a sua comercialização impactam na perda de qualidade e contribuem para o aumento no preço [37].

Gandra ${ }^{[42]}$ estudou o mercado de pescado da Região Metropolitana de Manaus. Por meio da soma da produção de pesca extrativa e da piscicultura, estimou o consumo médio anual per capita em 33,7 kg em 2009.

Cerdeira et al. [43] estudaram o consumo de pescado e de outros alimentos pela população ribeirinha do Lago Grande de Monte Alegre, na Região Norte. Foi realizada a coleta mensal de dados, por meio de formulários, durante um período de dois anos, envolvendo 35 famílias de 17 comunidades, que se dedicavam à pesca ou não. Os autores encontraram, em média, o consumo de pelo menos uma porção de pescado por dia em seis dias por semana e um consumo médio anual de 134,7 kg per capita.

Isaac \& Almeida [34] resgataram informações sobre o consumo de pescado na Amazônia brasileira em 39 publicações, das quais 25 apresentavam valores de ingestão. Foram considerados para o estudo os sete Estados que compõem a Amazônia brasileira (Acre, Amapá, Amazonas, Pará, Mato Grosso, Rondônia e Roraima). Os autores encontraram valores que variaram de $18,3 \mathrm{~kg} /$ per capita/ano, no interior do Amazonas, a $294 \mathrm{~kg} /$ per capita/ano, na região do Alto Solimões.

Tabela 2. Consumo pessoal* de pescado nas grandes regiões brasileiras em 2008/2009

\begin{tabular}{l|c|c|c|c|c|c}
\hline \multirow{2}{*}{\multicolumn{1}{c}{ Tipo }} & \multicolumn{7}{c}{ Regiões } \\
\cline { 2 - 7 } & Brasil & Norte & Nordeste & Sudeste & Sul & Centro-Oeste \\
\hline Pescado total & 10,0 & 38,1 & 14,6 & 5,4 & 3,1 & 3,4 \\
Peixes frescos e preparações & 8,5 & 34,7 & 12,8 & 4,2 & 2,5 & 3,1 \\
Peixes em conserva & 0,1 & 0,2 & 0,2 & 0,1 & 0,0 & 0,1 \\
Peixes salgados & 1,1 & 2,5 & 1,4 & 0,9 & 0,3 & 0,2 \\
Outros pescados & 0,3 & 0,8 & 0,2 & 0,2 & 0,3 & 0,0 \\
\hline
\end{tabular}

* Quantidade em quilograma por ano.

Fonte: IBGE [31]. 
Murrieta \& Dufour ${ }^{[44]}$ avaliaram o consumo de alimentos nas comunidades de Aracampina e São Benedito, na ilha de Ituqui, município de Santarém (Pará). Foi utilizado o método recordatório de 24 horas e a amostra abrangeu 12 domicílios e 42 indivíduos. $O$ consumo diário de pescado foi relatado e os autores observaram que os alimentos básicos da dieta estavam perdendo importância relativa para produtos industrializados (frequentemente mais ricos em energia) adquiridos na cidade. Com base nesses dados, Isaac \& Almeida [34] estimaram um consumo médio anual per capita que variou de $186,5 \mathrm{~kg}$ a $234,7 \mathrm{~kg}$, de acordo com o gênero (masculino e feminino) e com a comunidade (Aracampina e São Benedito).

Faganello [45] analisou a disponibilidade domiciliar per capita por dia de grupos de alimentos e a variação desta de acordo com o rendimento de famílias das regiões metropolitanas de São Paulo e Recife. Foram utilizados dados divulgados pelo IBGE, por meio da POF 1995/1996. Os resultados obtidos da participação relativa de peixes na disponibilidade de energia foram baixos nas duas regiões metropolitanas, em todas as faixas de renda, variando de 0,8 a 1,3\% na região metropolitana de São Paulo, e de 0,6 a 0,7\% na região metropolitana de Recife. Comparativamente, a participação da carne bovina variou entre 4,8 e 8,9\% em São Paulo e entre 1,6 a 10,3\% em Recife. Cabe a informação de que o valor energético total (VET) obtido em São Paulo foi menor do que o obtido em Recife (1.063 a $1.761 \mathrm{kcal}$ versus 1.256 a $2.254 \mathrm{kcal})$. Deve ser considerado também o fato das análises não envolverem o consumo fora de domicilio.

Tendo por base dados obtidos no Estado de São Paulo, Maciel et al. ${ }^{[46]}$ descreveram as características dos consumidores e não consumidores de pescado em uma comunidade universitária paulista $(n=1.966)$, por meio da adoção de questionários preenchidos on line por voluntários. As autoras verificaram que, apesar de $94,9 \%$ consumirem pescado, apenas $27 \%$ o faziam regularmente, ou seja, ao menos uma porção por semana, e que o percentual de voluntários que consomem pescado duas ou mais vezes por semana não ultrapassou $17,4 \%$ em nenhum campus envolvido.

Gonçalves et al. [47], com o objetivo de identificar aspectos qualitativos do consumo de pescado em Porto Alegre, aplicaram questionários por correspondência em uma amostra representativa de habitantes de todos os setores da cidade $(n=512)$. Os autores encontraram que: $98,2 \%$ dos voluntários consumiam pescado; os entrevistados com idade inferior a 20 anos tinham preferência por peixes congelados, empanados e processados (nuggets) e os com idade entre 31 e 40 anos consumiam mais peixe em postas.

Minozzo et al. ${ }^{[48]}$ realizaram pesquisa de opinião sobre o consumo de pescado. Foi utilizado um questionário e a amostra $(n=583)$ foi composta por indivíduos dos municípios de São Paulo, Curitiba e Toledo. O pescado de água doce indicado como o mais consumido nas três cidades foi a tilápia e o pescado de água salgada foi o atum, em Toledo e Curitiba, e o cação, em São Paulo. Com relação à frequência, a proporção de indivíduos que informou consumir pescado mais de três vezes por mês foi $49,69 \%$, $30,81 \%$ e $28,86 \%$ em São Paulo, Toledo e Curitiba, respectivamente.

Considerando o perfil de consumo com base na variedade de espécies de pescado, a análise dos dados de aquisição de pescado do IBGE, por meio da POF 2008/2009 [18], mostra que o pescado de água doce é preferido na região Norte (10,95 kg versus 5,22 $\mathrm{kg}$ de pescado de água salgada) e o contrário é observado nas regiões Sul e Sudeste $(1,49 \mathrm{~kg}$ e 0,96 kg de pescado de água salgada versus $0,31 \mathrm{~kg}$ e $0,40 \mathrm{~kg}$ de pescado de água doce, respectivamente). Nordeste e Centro-Oeste atingiram 2,39 kg e 0,62 kg para pescado de água salgada e 1,61 $\mathrm{kg}$ e 0,64 $\mathrm{kg}$ para pescado de água doce, respectivamente. As regiões também apresentam particularidades, considerando as espécies de peixes mais consumidas: jaraqui, tucunaré, bagre e dourada são destaque na região Norte e apresentam consumo inexpressivo nas demais regiões. $\mathrm{O}$ mesmo acontece com a espécie de água doce acará, nas regiões Norte e Nordeste, e com o bacalhau na região Sudeste. Apenas na região Centro-Oeste, as espécies de água doce piau e anujá são mais presentes na pauta de aquisição das familias. Por outro lado, alguns peixes aparecem entre os mais consumidos na totalidade do território ou em pelo menos quatro das cinco grandes regiões. É o caso do camarão, da sardinha fresca e em conserva (exceto região Norte) e da pescada (exceto região Sul).

\section{CONSIDERAÇÕES FINAIS}

A ingestão de pescado está relacionada a benefícios à saúde humana e os riscos de prejuízo via contaminação por elementos químicos são considerados reduzidos, segundo estudos realizados com amostras de peixes comercializados no Brasil. 
De um modo geral, pode-se inferir que a disponibilidade e o consumo per capita no país são reduzidos e que não houve ampliação expressiva da aquisição entre 1970-2009, o que diferiu da tendência mundial observada no período. O pescado é obtido, em geral, fresco.

A região Norte apresenta elevada disponibilidade de pescado, tanto em áreas urbanas (região metropolitana de Manaus), quanto em comunidades de povos ribeirinhos. $\mathrm{O}$ acesso facilitado a alimentos processados, porém, pode alterar os hábitos alimentares desses povos.

A região Nordeste revela consumo acima da média nacional, embora a disponibilidade na região metropolitana de Recife seja baixa e próxima daquela encontrada na região metropolitana de São Paulo. As regiões Sul, Sudeste e Centro-Oeste apresentam consumo abaixo da média nacional.

A preferência por pescado de água doce é observada na região Norte, enquanto nas regiões Sul e Sudeste, o pescado de água salgada é mais facilmente encontrado nos domicílios. As espécies adquiridas também variam de acordo com a região.

Os benefícios nutricionais provenientes do consumo regular de pescado e o seu baixo consumo reforçam a validade de investimentos e incentivos por meio de políticas públicas para o aumento da disponibilidade e consumo deste alimento no Brasil, assim como a manutenção do padrão de ingestão nas regiões Norte e Nordeste.

\section{REFERÊNCIAS}

[1] Ababouch L. Fisheries and Aquaculture topics. Composition of fish. Topics Fact Sheets. In: FAO Fisheries and Aquaculture Department. Rome: FAO; 2005 [cited 2012 Oct 20]. Available from: http://www.fao.org/fishery/topic/12318/en

[2] Burger J. Fishing, fish consumption and awareness about warnings in a university community in central New Jersey in 2007, and comparisons with 2004. Environ Res. 2008;108(1):107-16.

[3] Harvard. School of Public Health. The Nutrition Source. Omega-3 Fatty Acids: an essential contribution [cited 2012 Oct 22]. Available from: http://www.hsph.harvard.edu/nutritionsource/what-shouldyou-eat/omega-3-fats/index.html
[4] Food and Agriculture Organization. The State of World Fisheries and Aquaculture. Fisheries and Aquaculture Department. Rome: FAO; 2009.

[5] Trondsen T, Scholderer J, Lund E, Eggen AE Perceived barriers to consumption of fish among Norwegian women. Appetite. 2003;41(3):301-14.

[6] Brasil. Ministério da Agricultura, Pecuária e Abastecimento. Decreto no 30.691, de 29 de março de 1952. Aprova o novo Regulamento da Inspeção Industrial e Sanitária de Produtos de Origem Animal. Diário Oficial da União, Brasília, 7 jul. 1952. Seção 1, p. 10785.

[7] Stansby ME. Polyunsaturates and fat in fish flesh. J Am Diet Assoc. 1973;63:625-630.

[8] Bang HO, Dyerberg J. Plasma lipids and lipoproteins in Greenlandic West-coast Eskimos. Acta Med Scand. 1972;1(92):85-94.

[9] Bang HO, Dyerberg J, Hjorne N. The composition of food consumed by Greenland Eskimos. Acta Med Scand. 1976;200:69-73.

[10] Simopoulos AP. Omega-3 fatty acids in health and disease and in growth and development. Am J Clin Nutr. 1991;54:438-63.

[11] Oetterer M. Proteínas do pescado. Universidade de São Paulo [acesso em 24 out 2012]. Disponível em: http://www.esalq.usp.br/departamentos/lan/pdf/Proteinas \%20pescado.pdf

[12] Ababouch L. Fisheries and Aquaculture topics. Chemical elements of fish. Topics Fact Sheets. In: FAO Fisheries and Aquaculture Department. Rome: FAO; 2005 [cited 2012 Oct 20]. Available from: http://www.fao.org/fishery/topic/14820/en

[13] Ackman RG. Characteristics of the fatty acid composition and biochemistry of some fresh-water fish oils and lipids in comparison with marine oils and lipids. Comp Biochem Physiol. 1967;22:907-22.

[14] Viswanathan-Nair PG, Gopakumar K. Fatty acid compositions of 15 species of fish from tropical waters. J Food Sci. 1978;43:1162-1164.

[15] Agren J, Muje P, Hanninen O, Herranen J, Penttila I. Seasonal variations of lipid fatty acids of boreal freshwater fish species. Comp Biochem Physiol. 1987;88(3):905-09.

[16] Wang YJ, Miller LA, Perren M, Addis PB. Omega-3 fatty acids in Lake Superior fish. J Food Sci. 1990;55(1):71-76. 
[17] European Food Safety Authority. Labelling reference intake values for $n-3$ and $n-6$ polyunsaturated fatty acids. Scientific Opinion of the Panel on Dietetic Products, Nutrition and Allergies on a request from the Commission related to labeling reference intake values for $n-3$ and $n-6$ polyunsaturated fatty acids. The EFSA Journal. 2009;1176:111.

[18] Instituto Brasileiro de Geografia e Estatística. Pesquisa de Orçamentos Familiares 2008-2009: Aquisição alimentar domiciliar per capita. Rio de Janeiro: IBGE; 2010.

[19] Núcleo de Estudos e Pesquisas em Alimentação. Universidade Estadual de Campinas (NEPA/UNICAMP). Tabela Brasileira de Composição de Alimentos (TACO): versão 1. São Paulo: NEPA/Unicamp; 2011.

[20] Dyerberg J, Bang HO, Stofferson E, Moncada S, Vane JR Eicosapentaenoic acid and prevention of thrombosis and atherosclerosis. Lancet. 1978;312(8081):117-19.

[21] Dyerberg J, Bang HO. Haemostatic function and platelet polyunsaturated fatty acids in Eskimos. Lancet. 1979;2(8140):433-35.

[22] Kris-Etherton PM, Harris WS, Appel LJ, American Heart Association. Fish consumption, fish oil, omega-3 fatty acids, and cardiovascular disease. Circulation. 2002;106(21):2747-57.

[23] Leaf A. Prevention of sudden cardiac death by $n-3$ polyunsaturated fatty acids. J Cardiovasc Med. 2007;8(Suppl 1):S27-29.

[24] Cosgrove JP, Church DF, Pryor WA. The kinetics of the autoxidation of polyunsaturated fatty acids. Lipids. 1987;22(5):299-304.

[25] Grim JM, Hyndman KA, Kriska T, Girotti AW, Crockett EL. Relatioship between oxidizable fatty acid content and level of antioxidant glutathione peroxidases in marine fish. J Exp Biol. 2011;214(22):3751-59.

[26] Oken E, Kleinman KP, Berland WE, Simon SR, RichEdwards JW, Gillman MW. Decline in fish consumption among pregnant women after a national mercury advisory. Obstet Gynecol. 2003;102(2):346-51.

[27] Codex Alimentarius International Food Standards. Report of the eighteenth session of the codex commitee on fish and fishery products. Bergen: Joint FAO and WHO standards programme; 1988.
[28] Kitahara SE, Okada IA, Sakuma AM, Zenebon O, Jesus RS, Tenuta-Filho A. Mercúrio total em pescado de água doce. Ciênc Tecnol Aliment. 2000;20(2):267-73.

[29] Morgano MA, Gomes PC, Mantovani DMB, Perrone AAM, Santos TF. Níveis de mercúrio total em peixes de água doce em pisciculturas paulistas. Ciênc Tecnol Aliment. 2005;25(2):250-53.

[30] Morgano MA, Perez ACA, Milani RF, Mantovani DMB, Neiva CRP, Furlan EF, et al. Mercúrio total em pescado da cadeia produtiva da Baixada Santista, estado de São Paulo, Brasil. Rev Inst Adolfo Lutz. 2007;66(2):164-71.

[31] Instituto Brasileiro de Geografia e Estatística. Pesquisa de Orçamentos Familiares 2008-2009: Análise do consumo alimentar pessoal no Brasil. Rio de Janeiro: IBGE; 2011.

[32] Faostat. Food and Agriculture Organization. Statistical database [cited 2012 Oct 16]. Available from: http://faostat.fao.org/site/610/DesktopDefault.aspx?PageI $\mathrm{D}=610$ \#ancor

[33] Brasil. Ministério da Pesca e Aquicultura. Boletim estatístico da pesca e aquicultura Brasil 2010. Brasília: MPA; 2012.

[34] Isaac VJ, Almeida MC. El consumo de pescado en la Amazonía Brasileña, Relatório FAO. Roma: FAO; 2011.

[35] World Health Organization. Protein and aminoacid requirements in human nutrition. Report of a joint WHO/FAO/UNU Expert Consultation, United Nations University. Technical Report Series, 935. WHO; 2007.

[36] Oetterer M. Industrialização do pescado cultivado. Guaíba: Agropecuária; 2002.

[37] Sonoda DY. Demanda por pescados no Brasil entre 2002 e 2003 [tese]. Piracicaba: Universidade de São Paulo; $2006.118 \mathrm{p}$.

[38] Levy-Costa RB, Sichieri R, Pontes NS, Monteiro CA. Disponibilidade domiciliar de alimentos no Brasil: distribuição e evolução (1974-2003). Rev Saúde Públ. 2005;39(4):530-40.

[39] Brasil. Ministério da Pesca e Aquicultura [acesso em 2 nov 2012] Disponível em: http://www.mpa.gov.br/index.php/imprensa/noticias/351mpa-faz-mapeamento-do-consumo-de-pescado-nas-escolaspublicas-brasileiras. 2012 
[40] Danelon MS. Estado nutricional, consumo alimentar e estilo de vida de escolares de Campinas - SP [dissertação]. Piracicaba: Universidade de São Paulo; 2007. 230 p.

[41] Caroba DCR. A escola e o consumo alimentar de adolescentes matriculados na rede pública de ensino [tese]. Piracicaba: Universidade de São Paulo; 2002. 161 p.

[42] Gandra AL. O mercado de pescado da região metropolitana de Manaus, Relatório INFOPESCA. Série: O mercado de pescado nas grandes cidades latino-americanas. Montevidéu: INFOPESCA; 2010.

[43] Cerdeira RGP, Refino ML, Isaac VJ. Consumo de pescado e outros alimentos pela população ribeirinha do lago Grande de Monte Alegre. Acta Amaz. 1997;27(3):213-27.

[44] Murrieta RSS, Dufour DL. Fish and farina: protein and energy consumption in Amazonian rural communities on Ituqui Island, Brazil. Ecol Food Nutr. 2004;43(3):231-55.

[45] Faganello CRF. Disponibilidade de energia e nutrientes para a população das regiões metropolitanas de Recife e São Paulo [dissertação]. Piracicaba: Universidade de São Paulo; 2002. $113 \mathrm{p}$.

[46] Maciel ES, Vasconcelos JS, Sonati JG, Savay-da-Silva LK, Galvão JA, Oetterer M. Perfil dos voluntários de universidade brasileira a respeito do consumo de pescado. Seg Alim Nutr. 2012;19(1):60-70.

[47] Gonçalves AA, Passos MG, Biedrzycki A. Tendência do consumo de pescado na cidade de Porto Alegre: um estudo através de análise de correspondência. Estudos tecnológicos. 2008;4(1):21-36.

[48] Minozzo MG, Haracemiv SMC, Waszczynskji N. Perfil dos consumidores de pescado nas cidades de São Paulo (SP), Toledo (PR) e Curitiba (PR) no Brasil. R Alim Hum. 2008;14(3);133-40. 